\title{
Arterial stiffness in black African ancestry patients with chronic kidney disease living in Cameroon
}

\author{
Daniel Lemogoum $^{1,2,3}$, Marie Patrice Halle ${ }^{1,4}$, Ruth Dione Mboule ${ }^{1,3}$, Philippe Van de Borne ${ }^{2}$, Elysée \\ Claude Bika Lele ${ }^{3}$, Felicité Kamdem ${ }^{1,4}$, Marie Solange Doualla ${ }^{4}$, Henry Luma ${ }^{4}$, Michel P. Hermans ${ }^{5}$, Luc \\ Van Bortel ${ }^{6}$
}

${ }^{1}$ Faculty of medicine and Pharmaceutical Sciences, University of Douala, Douala, Cameroon; ${ }^{2}$ ULB-Erasme Hospital, Université Libre de Bruxelles, Brussels, Belgium; ${ }^{3}$ Cameroon Heart Foundation, Douala, Cameroon; ${ }^{4}$ Department of Internal Medicine, Douala General Hospital, Douala, Cameroon; ${ }^{5}$ Endocrinology and Nutrition Unit, Cliniques Universitaires St-Luc, Université Catholique de Louvain, Avenue Hippocrate, Brussels, Belgium; ${ }^{6}$ Heymans Institute of Pharmacology, Ghent University, Ghent, Belgium

Contributions: (I) Conception and design: D Lemogoum, MP Halle, RD Mboule, L Van Bortel; (II) Administrative support: D Lemogoum, MP Halle, MS Doualla, F Kamdem, H Luma, P Van de Borne; (III) Provision of study material or patients: D Lemogoum, P Van de Borne, MP Hermans, L Van Bortel, MP Halle; (IV) Collection and assembly of data: D Lemogoum, MP Halle, RD Mboule, EC Bika Lele, F Kamdem, L Van Bortel; (V) Data analysis and interpretation: D Lemogoum, MP Halle, RD Mboule, EC Bika Lele, P Van de Borne, L Van Bortel, MP Hermans; (VI) Manuscript writing: All authors; (VII) Final approval of manuscript: All authors.

Correspondence to: Prof. Daniel Lemogoum. Service of Cardiology, ULB-Erasme Hospital, Université Libre de Bruxelles, 808 , Lennik Road, 1070 Brussels, Belgium. Email : dlems2002@yahoo.fr.

Background: Increased aortic pulse wave velocity (PWV), a direct measure of arterial stiffness (AS) is an independent predictor of cardiovascular events (CVEs) in chronic kidney disease (CKD) patients. This study assessed the patterns of PWV among Cameroonian patients with CKD in whom that marker of early vascular aging has not been explored so far.

Methods: We enrolled 150 Black African patients (mean age: $52 \pm 15$ years, $56.7 \%$ males) with CKD in a cross-sectional study conducted at Douala General Hospital, Douala, Cameroon. Sociodemographic, anthropometric and biologic variables, blood pressure (BP) and PWV were recorded in all participants. Estimated aortic PWV was measured using a Mobil-O-Graph automatic brachial oscillometric device.

Results: PWV increased with aging $(\mathrm{P}<0.0001)$, and $\mathrm{PWV}$ adjusted for age, sex, body mass index and mean arterial BP (MAP) was higher in non-dialysed $(n=90)$ than in hemodialysed $(n=60)$ patients, even in predialysis: $8.5 \pm 2.0$ vs. $7.9 \pm 1.4 \mathrm{~m} / \mathrm{s}(\mathrm{P}=0.026)$; and in post-dialysis: $8.5 \pm 2.0$ vs. $7.8 \pm 1.5 \mathrm{~m} / \mathrm{s}(\mathrm{P}=0.008)$. The mean PWV of all study participants was $8.2 \pm 1.8 \mathrm{~m} / \mathrm{s}$, with $61.3 \%$ of patients having a $\mathrm{PWV} \geq 8.2 \mathrm{~m} / \mathrm{s}$, indicative of subclinical damage to the aorta, which was more pronounced in non-dialysis $(67.8 \%)$ than in hemodialysis $(53.3 \%)$ patients $(\mathrm{P}=0.033)$. Multivariable analysis performed in all participants revealed that advanced age, MAP and tobacco use were independently associated with $\mathrm{PWV}$ (all $\mathrm{P}<0.05)$.

Conclusions: Our findings suggest increased AS in Cameroonian CKD non-dialyzed as compared to dialyzed patients. Slower PWV in patients on maintenance hemodialysis suggests improvement of aortic distensibility following dialysis. However, further large-scale studies are needed to confirm our findings and to improve understanding of the underlying mechanisms of arterial stiffening in black African ancestry patients with CKD.

Keywords: Arterial stiffness (AS); chronic kidney disease (CKD); hemodialysis; Mobil-O-graph; pulse wave velocity (PWV); Cameroon

Submitted Feb 11, 2018. Accepted for publication Apr 02, 2018.

doi: $10.21037 / \mathrm{cdt} .2018 .04 .04$

View this article at: http://dx.doi.org/10.21037/cdt.2018.04.04 


\section{Introduction}

Chronic kidney disease (CKD) is a growing worldwide public health challenge and represents a major cause of death, with the fastest increase over the last two decades (1)]. Among the determinants of high mortality rate in CKD patients, cardiovascular disease (CVD) accounts for up to $50 \%$ of all deaths $(1,2)$. The high burden of CVD in CKD patients was ascribed to both conventional cardiovascular $(\mathrm{CV})$ risk factors such as age, hypertension, diabetes, obesity, smoking, and dyslipidemia; and non-traditional or emerging risk factors which include arterial stiffness (AS) (3). Structural and functional changes in arteries are important features of CVD (4). The process of CV damage starts very early during CKD progression, long before end-stage renal disease (ESRD) is reached (1). Increased AS corresponds to damage of large arteries and was shown to be a significant predictive factor of all-cause and CV mortality in different populations (5), including patients with ESRD (3,6-8). Moreover, increased pulse wave velocity (PWV), which is the gold standard measure of AS (9), was shown to contribute to all-cause $(5,7)$ and CV mortality in ESRD patients (6-8). PWV is linked to arterial wall structure and function, and is essentially influenced by age-related changes, blood pressure (BP) and other pathologic states such as CKD (4,6-8). Several mechanisms including those related to CKD have been suggested to be involved in accelerated vessel stiffening (3,8,10-13). Identified factors associated with increasing PWV in non-dialysed CKD patients are age, black ethnicity, male gender, hypertension and diabetes mellitus (13-16). Evidence indicates that stiffening of the aorta may decrease in patients on maintenance dialysis (17).

Despite the growing burden of CKD faced by many subSaharan African (SSA) countries, with an overall estimated CKD prevalence reaching $13.6 \%$ among adults (18), little is known about the prevalence and incidence of CVD in Black African patients with CKD. While hypertension and diabetes have been identified as common CV risk factors among CKD patients in Africa (18-20), data related to AS and CV outcomes in these patients have been poorly explored to date, especially in Cameroon. The present study aimed to assess the patterns of AS measured by PWV among black African ancestry CKD patients living in Cameroon.

\section{Methods}

\section{Study design and data collection}

Between October 2015 and May 2016, 150 CKD patients
(56.7\% males, mean age $52 \pm 15$ years) comprising 90 nondialysed and 60 hemodialysed patients were consecutively recruited in a cross-sectional study conducted in the hemodialysis unit of Douala General Hospital, Douala, Cameroon. To be included patients had to meet the Kidney Disease Outcomes Quality Initiative (KDOQI) criteria for CKD stages 1 to 5, with estimated glomerular filtration rate (eGFR) calculated using the Chronic Kidney Disease Epidemiology Collaboration (CKD-EPI) equation and/ or be on chronic hemodialysis (21). Exclusion criteria included: acute disease requiring hospitalization at the time of patient enrolment; evidence of stenosis of the subclavian artery of the arm without shunt or of the nonshunt arm chosen to be used for the Mobil-O-Graph measurements; atrial fibrillation, mental illness; inability to understand the information presented and to sign the informed consent. A questionnaire was used to assess sociodemographic variables, education level, patients' medical history (comorbidities, etiology of CKD, duration on dialysis, ongoing medications) and lifestyle data. Previously documented cardiovascular events (CVE) such as myocardial infarction, stroke, transient ischemic attack, peripheral vascular disease or heart failure were also recorded. Physical examination included measurements of $\mathrm{BP}$, heart rate (HR), waist circumference (WC), body weight, and height. Body weight was measured in kilogram $(\mathrm{kg})$, and height in meter $(\mathrm{m})$ was measured to the nearest $0.5 \mathrm{~cm}$ with a fixed stadiometer. Body mass index (BMI; $\left.\mathrm{kg} / \mathrm{m}^{2}\right)$ was calculated as weight $(\mathrm{kg})$ divided by the square of height $(\mathrm{m})$. Overweight was defined as a $\mathrm{BMI} \geq 25 \mathrm{~kg} / \mathrm{m}^{2}$, and obesity as a $\mathrm{BMI} \geq 30 \mathrm{~kg} / \mathrm{m}^{2}$. Abdominal obesity was defined as $W C$ $\geq 102 \mathrm{~cm}$ for men and $\geq 88 \mathrm{~cm}$ for women (22).

All hemodynamic measurements were performed, after 15 minutes rest, in the sitting position and in standardized conditions (23). BP and PWV were recorded on the dominant arm and/or on the arm contralateral to the arteriovenous shunt in non dialysed and hemodialysed patients, respectively. Peripheral and central aortic systolic, diastolic and mean arterial BP (MAP), HR, and PWV were measured using a validated brachial cuff-based oscillometric method based on mathematical transformation of brachial pressure waveforms, using a common cuff (Mobil-OGraph, I.E.M., Stolberg, North Rhine-Westphalia, Germany); which is a non-operator dependent automatic device. Two consecutive measurements were taken at time intervals of $\geq 5$ minutes, using a cuff's width adjusted to the arm's circumference. The mean of the nearest two accurate hemodynamic readings was used. The reliability 
of the Mobil-O-Graph in estimating the PWV by PWA (MobPWV) was demonstrated in previous studies $(24,25)$. The device was approved by the Food and Drug Administration, with its BP detection unit validated according to the British Hypertension Society (26) and the European Society of Hypertension (27) recommendations. Pulse pressure (PP) was calculated as systolic minus diastolic BP. All procedures were performed by a single medical investigator. In dialysis patients, measurements were taken on dialysis day (prior to dialysis session; pre-dialysis measurement), and thereafter 24 hours after last dialysis (post-dialysis measurement).

Hypertension was defined as systolic $\mathrm{BP} \geq 140 \mathrm{mmHg}$ and/ or diastolic $\mathrm{BP} \geq 90 \mathrm{mmHg}$ or ongoing antihypertensive medication. A standard carotid-femoral PWV (cfPWV) $\geq 10 \mathrm{~m} / \mathrm{s}$ obtained by direct measurement method was proposed as indicative of subclinical aortic damage (22). The Mobil-O-Graph device used in this study provides an indirect measure of aortic PWV (mobPWV). Few studies have compared mobPWV and cfPWV. In hemodialysis patients, Sarafidis et al. (25) found that MobPWV gave lower values $(-0.8 \mathrm{~m} / \mathrm{s})$ than Sphygmocor cfPWV (10.3 vs. $9.5 \mathrm{~m} / \mathrm{s}$, respectively), with Sphygmocor values obtained with subtracted distance using the suprasternal notch. Since the subtracted distance method underestimates standard cfPWV by $10 \%$ (28), and considering these findings, the cutoff value for MobPWV should be $8.2 \mathrm{~m} / \mathrm{s}$ instead of $10 \mathrm{~m} / \mathrm{s}$ ( $10 \%$ underestimation by the subtracted distance method amounting to $9 \mathrm{~m} / \mathrm{s}$ minus $0.8 \mathrm{~m} / \mathrm{s}$ lower values with MobPWV, yielding a figure of $8.2 \mathrm{~m} / \mathrm{s}$ ).

Blood samples were collected after an 8-hour overnight fast and sent to the biochemistry laboratory of Douala General Hospital for analysis. Serum creatinine, uricemia, calcium, phosphorus, hemoglobin, fasting plasma glucose (FPG), total cholesterol, triglycerides, high-density lipoprotein (HDL) cholesterol, and low-density lipoprotein (LDL) cholesterol values were measured using enzymatic colorimetric methods. Blood samples were collected before dialysis sessions in hemodialysis patients.

Diabetes mellitus was defined as FPG $\geq 1.26 \mathrm{~g} / \mathrm{L}$ and/ or being on glucose-lowering medication(s) (29). Smoking status was defined as never, former or current smoking, the latter also including occasional smokers. Alcohol use was defined as having at least one alcoholic drink per week, and classified along three categories: never, former and current users.

Kidney disease was defined using the KDOQI definition for CKD (21), i.e., lowering of eGFR and/or the presence of (micro) albuminuria. Each patient was classified into one of 5 CKD stages: stage 1: kidney damage with normal or increased eGFR (>90 mL/min/1.73 $\left.\mathrm{m}^{2}\right)$; stage 2: mild decreased in eGFR $\left(60-89 \mathrm{~mL} / \mathrm{min} / 1.73 \mathrm{~m}^{2}\right)$; stage 3 : moderate reduction in eGFR $\left(30-59 \mathrm{~mL} / \mathrm{min} / 1.73 \mathrm{~m}^{2}\right)$; stage 4 : severe reduction in eGFR $\left(15-29 \mathrm{~mL} / \mathrm{min} / 1.73 \mathrm{~m}^{2}\right)$; stage 5: kidney failure (eGFR $<15 \mathrm{~mL} / \mathrm{min} / 1.73 \mathrm{~m}^{2}$ and/or chronic dialysis). The chronic hemodialysis group consisted of all patients with stage 5 CKD (eGFR $\left.\leq 15 \mathrm{~mL} / \mathrm{min} / 1.73 \mathrm{~m}^{2}\right)$ and on hemodialysis as renal replacement therapy.

Participation to the survey was voluntary and written signed informed consent was taken from all the patients before inclusion. The study was approved by the Ethical Institutional Research Board of the University of Douala, Cameroon (No. CEI-UD/362/12/2015/T).

\section{Statistical analysis}

Statistical analysis was performed using the Statistical Package for the Social Sciences version 20.0 software (SSPS Inc, Chicago, Illinois, USA). Quantitative data are presented as mean \pm standard deviation (SD), and qualitative data are presented as frequencies or percentages. Comparison of quantitative data between non-dialyzed and hemodialysed patients was performed using Student $t$-test and qualitative data were compared using Chi square test. For comparison of hemodynamic parameters between pre- and post-dialysis, we used the non-parametric Wilcoxon rang test. Estimated standard cfPWV and mobPWV were adjusted for major confounders including age, sex, MAP and BMI in both nondialysed CKD and hemodialysis participants using linear regression equation. A multiple regression analysis was performed to assess independent determinants of $\mathrm{PWV}$. All relevant variables correlated with $\mathrm{PWV}$ (at least $\mathrm{P}<0.1$ ) were included in the model. Statistical significance was considered for $\mathrm{P}<0.05$.

\section{Results}

\section{Baseline characteristics}

As shown in Table 1, non-dialysed patients were older $(\mathrm{P}=0.009)$ and more had a $\mathrm{BMI}>25 \mathrm{~kg} / \mathrm{m}^{2}(0.012)$ than patients on maintenance dialysis. Most non-dialysed patients $(33.3 \%)$ were in CKD stage 5 or CKD stage 4 (25.6\%). Hypertension was the most frequent $\mathrm{CV}$ risk factor among study participants, followed by type 2 diabetes mellitus. Mean hemoglobin was lower in hemodialysis 
Table1 Baseline characteristics of the study population

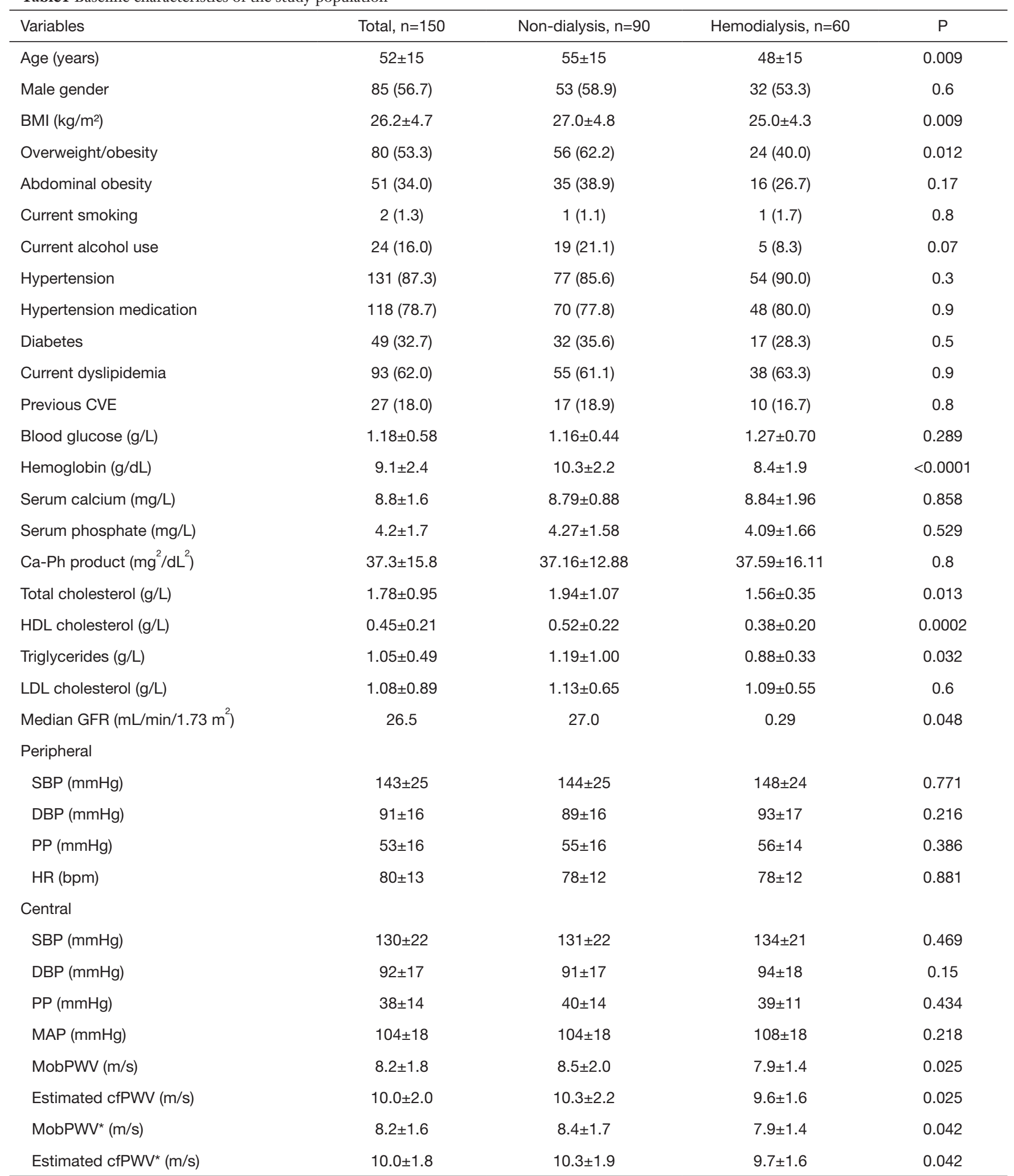

Data are mean \pm standard deviation or number (percentages); $\mathrm{PWV}^{\star}$, pulse wave velocity adjusted for age, MAP, sex, body mass index. HDL, high-density lipoprotein; LDL, non-high-density lipoprotein; Ca-Ph, calcium-phosphate; CVE, cardiovascular event. 


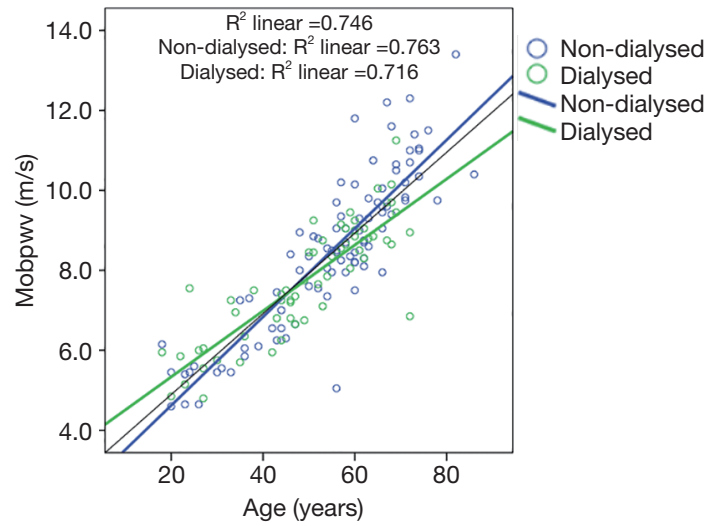

Figure 1 Correlation between age and pulse wave velocity in both non-dialysed and hemodialysed patients.

patients $(\mathrm{P}<0.0001$ vs. non-hemodialysis patients), whereas total cholesterol, triglycerides and HDL-cholesterol were significantly higher in non-dialysis than in hemodialysis patients (all $\mathrm{P}<0.05)$. Alcohol consumption rate was slightly higher in non-dialysis than in hemodialysis patients $(\mathrm{P}=0.07)$. Peripheral as well as central SBP, DBP, PP and MAP were similar between non-dialyzed and hemodialyzed patients. MobPWV and estimated cfPWV were significantly higher in non-dialyzed than in hemodialyzed patients, even after adjustment for age and $\mathrm{BMI}$ (all $\mathrm{P}<0.05$ ).

\section{Hemodynamic variables}

PWV increased significantly $(\mathrm{P}=0.002)$ with aging in both non-dialysis and hemodialysis patients (Figure 1). After adjustment for age, MAP, sex and BMI, estimated of PWV was markedly higher in non-dialysis than in hemodialyzed patients, even in pre-dialysis $(\mathrm{P}=0.026)$ and in post-dialysis $(\mathrm{P}=0.008)$ (Table 1), suggesting that chronic dialysis may favourably impact AS. MAP and both peripheral and central systolic and diastolic BP were similar between the two groups. As illustrated in Table 2, hemodialysis acutely and significantly decreased peripheral PP (by $6 \mathrm{mmHg}$; $\mathrm{P}=0.008$ ), and increased HR (by approximately $5 \mathrm{bpm}$; $\mathrm{P}=0.001)$.

As shown in Figure 2, 61.3\% of the total study population exhibited age, MAP, sex and BMI-adjusted PWV: MobPWV $\geq 8.2 \mathrm{~m} / \mathrm{s}$; estimated standard cfPWV $\geq 10.0 \mathrm{~m} / \mathrm{s}$, suggesting subclinical aortic damage. Most participants with high $\mathrm{PWV}$ were non-dialysed patients $(\mathrm{P}=0.033)$.

$P W V$ according to $C V$ risk factors and other CKD-related

\section{parameters}

In the overall study population (Table 3), PWV was higher in patients aged $\geq 50$ years, in hypertensive patients and/or in diabetic patients with $\mathrm{CKD}$ (all $\mathrm{P}<0.01$ ) and with a trend for higher $\mathrm{PWV}$ in patients with previous $\mathrm{CVE}(\mathrm{P}=0.064)$. There was no significant difference between those in CKD stage 5 and those in early CKD stages.

\section{Determinants of aortic PWV}

As illustrated in Table 4, multivariable regression analysis performed in the total study population, and in nondialyzed group taken separately revealed that advanced age, MAP and current smoking were positively and independently associated with $\mathrm{PWV}$ (all $\mathrm{P}<0.05$ ). In the hemodialysis group in predialysis as well as in post dialysis, older age, MAP and diabetes emerged as independent correlates of $\mathrm{PWV}(\mathrm{P}<0.05)$.

\section{Discussion}

We are not aware of another study exploring aortic stiffness as assessed by PWV estimated by Mobil-O-Graph in CKD patients born and living in Cameroon, and this study provides direct evidence of higher age, MAP, sex and BMI adjusted $\mathrm{PWV}$ in non-dialysis patients $v s$. those on chronic maintenance dialysis. AS was mostly driven by age, BP, tobacco use and diabetes. It should be noted that high-risk patients exhibiting increased PWV, a major vascular aging biomarker suggestive of subclinical aortic damage, were mostly found among non-dialysed patients.

Increased AS was reported in both normotensive and hypertensives black populations (30), as well as in the present study of black Cameroonian indigenous CKD patients, especially in the non-dialysed patients. Our findings are in line with previous observations of Caucasian patients with CKD, in whom early vascular ageing, characterized by aortic stiffening combined with outward arterial remodeling, was observed according to progression of CKD and in ESRD (11-13). Increased arterial stiffening in CKD patients is the result of aging and of non-specific and ESRD related risk factors, such as medial calcification, volume overload, uraemia-related endothelial dysfunction, increased extracellular matrix and intimal fibroelastic thickening $(13,31)$. Our findings also in the line of Shinohara et al. (32), who previously reported 
Table 2 Comparison of hemodynamic parameters between hemodialysed patients in pre-dialysis and in post dialysis

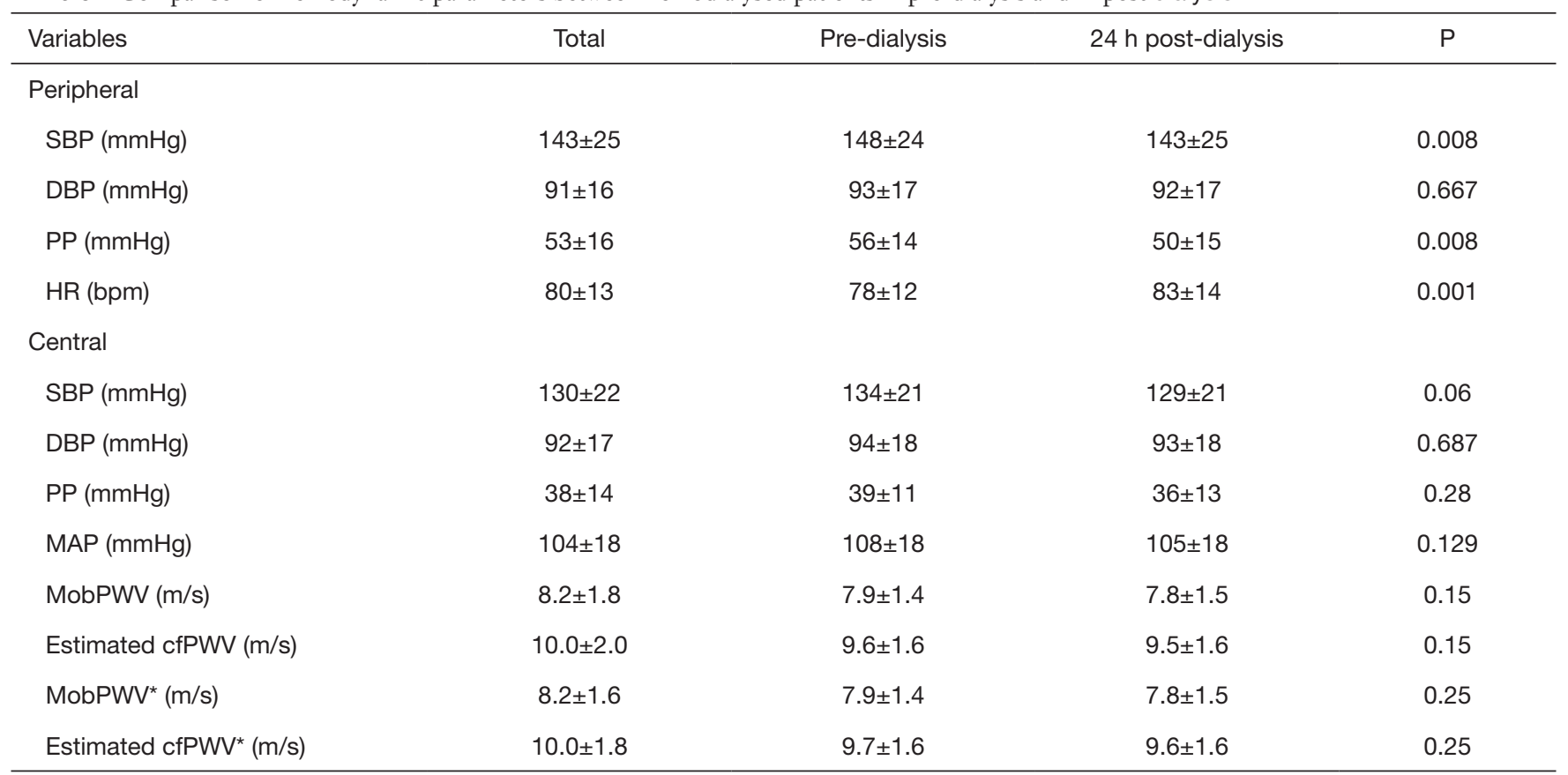

$\mathrm{PWV}^{\star}$, pulse wave velocity adjusted for age, MAP, sex, body mass index. HR, heart rate; HD, hemodialysis; SBP, systolic blood pressure, DBP, diastolic blood pressure, PP, pulse pressure, MAP, mean arterial blood pressure.

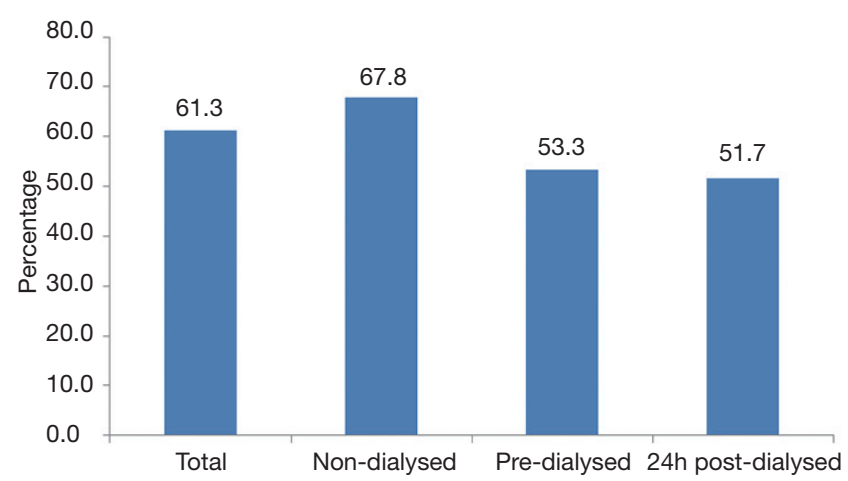

Figure 2 Proportion of patients with increased PWV (MobPWV $\geq 8.2 \mathrm{~m} / \mathrm{s}$; estimated standard cfPWV $\geq 10.0 \mathrm{~m} / \mathrm{s}$ ).

that predialysis CKD patients are more prone to accelerated arterial wall stiffening than chronic hemodialysis patients. It was suggested that hemodialysis could directly control or reduce some of the metabolic alterations underlying AS in patients with advanced CKD. Thus, hemodialysis patients show cyclic changes in PWV related to hydration status and $\mathrm{BP}$ values (33), with a recent study suggesting that daily
Table 3 Comparison of mean pulse wave velocity with cardiovascular risk factors and other parameters in the total study population

\begin{tabular}{lccc}
\hline Variables & No & Yes & $\mathrm{P}$ \\
\hline Age $\geq 50$ years & $6.9 \pm 3.4$ & $9.3 \pm 1.3$ & $<0.0001$ \\
Male sex & $8.6 \pm 3.0$ & $8.0 \pm 1.9$ & 0.7 \\
Smoking & $8.3 \pm 2.7$ & $9.1 \pm 1.8$ & 0.4 \\
Alcohol use & $8.3 \pm 2.8$ & $8.5 \pm 1.6$ & 0.7 \\
Overweight/obesity & $8.2 \pm 3.5$ & $8.6 \pm 1.6$ & 0.3 \\
Abdominal obesity & $8.2 \pm 3.0$ & $8.6 \pm 1.6$ & 0.3 \\
Hypertension & $6.8 \pm 1.7$ & $8.6 \pm 2.7$ & 0.005 \\
Diabetes & $7.8 \pm 2.9$ & $9.5 \pm 1.2$ & $<0.0001$ \\
Previous CV event & $8.3 \pm 2.8$ & $8.9 \pm 1.2$ & 0.064 \\
Anemia & $8.3 \pm 1.8$ & $8.6 \pm 2.8$ & 0.2 \\
High Ca-Ph & $8.6 \pm 2.8$ & $8.2 \pm 1.9$ & 0.5 \\
Dyslipidemia & $8.0 \pm 2.1$ & $8.6 \pm 2.9$ & 0.1 \\
Stage 5 CKD & $8.5 \pm 1.9$ & $8.3 \pm 3.0$ & 0.5 \\
\hline
\end{tabular}

Data are mean \pm standard deviation of pulse wave velocity. Ca$\mathrm{Ph}$, calcium phosphorus product. 
Table 4 Multivariable linear regression analysis of some factors correlating independently with pulse wave velocity

\begin{tabular}{|c|c|c|c|c|}
\hline Variables & All participants $(n=150)$ & Non-dialyzed $(n=90)$ & Pre-dialyzed $(n=60)$ & Post-dialyzed $(n=60)$ \\
\hline BMI $\left(\mathrm{kg} / \mathrm{m}^{2}\right)$ & $0.03 \pm 0.04$ & $-0.01 \pm 0.05$ & $0.06 \pm 0.07$ & $0.06 \pm 0.07$ \\
\hline MAP $(\mathrm{mmHg})$ & $0.23 \pm 0.04^{c}$ & $0.23 \pm 0.05^{c}$ & $0.36 \pm 0.08^{c}$ & $0.27 \pm 0.07^{b}$ \\
\hline Diabetes & $0.05 \pm 0.05$ & $0.00 \pm 0.05$ & $0.22 \pm 0.09^{b}$ & $0.22 \pm 0.09^{\mathrm{a}}$ \\
\hline Current smoking & $0.08 \pm 0.04^{a}$ & $0.09 \pm 0.05^{a}$ & $0.06 \pm 0.07$ & $0.07 \pm 0.07$ \\
\hline Adjusted $\mathrm{R}^{2}$ & 0.782 & 0.820 & 0.734 & 0.757 \\
\hline$P$ value for the model & $<0.0001$ & $<0.0001$ & $<0.0001$ & $<0.0001$ \\
\hline
\end{tabular}

${ }^{\mathrm{a}}, \mathrm{P}<0.05 ;{ }^{\mathrm{b}}, \mathrm{P}<0.01$; $^{\mathrm{C}}, \mathrm{P}<0.001$; Data are $\beta \pm \mathrm{SE}$. $\beta$, standard regression coefficient. SE, standard error; BMI, body mass index; CVE, cardiovascular event; MAP, mean arterial pressure.

dialysis may be used in patients with high PWV levels to reduce mortality risk (33).

Of note, advanced age emerged as independent determinant of increased PWV in the overall study population, as well as in non-dialysed and hemodialysed patients taken separately. Our findings are in line with previous surveys of Caucasian CKD patients which identified age as a strong and independent marker of increased AS (3,6-8,34). Arterial stiffening is an unavoidable participant to ageing processes. Thus, the aorta and large arteries become progressively less distensible with advancing age, with resultant reduced capacity to buffer pulsations from the contracting ventricle $(35,36)$.

We found that MAP, which reflects the steady component of BP, emerged as an independent marker of increased PWV. This observation fits with previous studies demonstrating that $\mathrm{BP}$ is a major determinant of PWV $(7,12,28,30,34)$. Indeed, aortic stiffening can at first be functional, resulting from higher BP without structural changes to the artery. Hypertension was also recognized as a major determinant of increased AS due to the associated medial hypertrophy which arises from chronic elevation of $\mathrm{BP}$, which is usually the case in CKD patients $(7,31,34)$, as well as in this study population, in which more than three quarter of patients were hypertensive.

Evidence also indicates that increased AS contributes to elevated PP, the dynamic component of BP, and inversely a decrease in $\mathrm{BP}$ can attenuate vascular stiffness (7). Thus, the lower PP observed following an hemodialysis session was in keeping with the lower PWV observed in ESRD patients on maintenance dialysis. However, the beneficial role of hemodialysis on AS is still debated (36). Some studies
$(37,38)$, but not all $(17,33)$ found a progressive increase of AS in hemodialysis patients. Part of the discrepancy among observations could be attributed to differences in study design. Our survey was strictly cross-sectional and had a relatively limited sample size. Differences in type of device used to assess aortic PWV, and possibly differences in age and comorbidity status of CKD patients could also represent confounders. However, our results establish unequivocally that a high proportion of Cameroonian patients with CKD exhibit major impairment in functional and structural large artery wall properties before initiation of hemodialysis.

Increased AS has also been reported in diabetic patients (12), and this was the case for Cameroonian CKD diabetic participants in this study. Yet diabetes, which was independently related to PWV in Caucasian CKD patients (34), emerged as independent determinant of PWV only in patients on maintenance dialysis, but not in nondialysed patients in our study, probably because PWV was adjusted for obesity, which is a major determinant of type 2 diabetes mellitus and which was more pronounced in nondialysed participants.

In Caucasian patients with CKD, some studies $(14,31,38-40)$, but not all $(11,13,17,33)$, reported increased PWV with declining kidney function assessed by eGFR, a validated marker of CKD progression. In the present survey, no association was observed between PWV and eGFR. This could be attributable, at least partly, to the limited sample size of the study population.

There are some limitations to this report. First, only cross-sectional data were included in the analysis, making 
impossible to draw any firm conclusions regarding the causality of the relationships between AS and the determinants identified. Long-term prospective study is needed to better characterize the impact of CKD on the natural history of AS and its determinants in CKD patients living in Cameroon. Secondly, being a single-centre study with limited sample size, the power to detect differences within our study population was constrained. Thirdly, we used the Mobil-O-graph which represents an oscillometric method for estimating aortic PWV. Few studies have used this device in CKD patients, and it may underestimate aortic PWV (25). Pending to its validation in Black African ancestry population, including patients with $\mathrm{CKD}$, our data should be interpreted with caution. A fourth limitation of this study was the absence of normal control subjects, which may allow to determine the impact of CKD on AS in black African indigenous patients living in Cameroon with this condition. A fifth limitation is the lack of correlations between PWV findings and other stiffness index such like left ventricular diastolic function as assessed by echocardiography. In mitigation, these limitations cannot alter the overall scope of our observations, since data were rigorously collected, and a single trained medical operator performed all measurements, eliminating inter-observer variability.

In conclusion, this study reveals higher aortic PWV in black Cameroonian non-dialysed CKD patients in comparison to those on maintenance dialysis. Slower PWV observed in patients on maintenance hemodialysis suggests that dialysis may contribute to improvement of their aortic distensibility. PWV was mainly modulated by advancing age, blood pressure, smoking and diabetes. However, further large-scale studies are needed to confirm our findings and to elicit underlying mechanisms of arterial stiffening in black African ancestry patients with CKD.

\section{Acknowledgements}

The authors express their grateful thanks to the survey officers, to all the participants to the survey, to the administrative and medical officers of the Douala General Hospital, to ULB-Erasme Hospital and to the Faculty of Medicine and Pharmaceutical Sciences of Douala University for continued support to clinical research on non-communicable diseases in Cameroon.

\section{Footnote}

Conflicts of Interest: The authors have no conflicts of interest to declare.

Ethical Statement: The study was approved by institutional ethics committee Board of the Douala University (No. 326) and informed consent was taken from all the patients.

\section{References}

1. Lozano R, Naghavi M, Foreman K, et al. Global and regional mortality from 235 causes of death for 20 age groups in 1990 and 2010: a systematic analysis for the Global Burden of Disease Study 2010. Lancet 2012;380:2095-128.

2. Vanholder R, Massy Z, Argiles A, et al. Chronic kidney disease as cause of cardiovascular morbidity and mortality. Nephrol Dial Transplant 2005;20:1048-56.

3. Covic A, Gusbeth-Tatomir P, Goldsmith DAJ. Arterial stiffness in renal patients: an update. Am J Kidney Dis 2005;45:965-77.

4. O'Rourke M. Mechanical principles in arterial disease. Hypertension 1995;26:2-9.

5. Vlachopoulos C, Aznaourikis K, Stefanadis. Prediction of cardiovascular events and all-cause mortality with arterial stiffness: a systematic review and meta-analysis. J Am Coll Cardiol 2010;55:1318-27.

6. Guerin AP, Blacher J, Pannier B, et al. Impact of aortic stiffness attenuation on survival of patients in end-stage renal failure. Circulation 2001;103:987-92.

7. Blacher J, Guerin AP, Pannier B, et al. Impact of aortic stiffness on survival in end-stage renal disease. Circulation 1999;99:2434-9.

8. Verbeke F, Maréchal C, Van Laecke S, et al. Aortic stiffness and central wave reflection predicts outcome in renal transplant recipients, Hypertension 2011;58:833-8.

9. Laurent S, Cockcroft J, Van Bortel L, et al. Expert consensus document on arterial stiffness: methodological issues and clinical applications. Eur Heart J 2006;27:2588-605.

10. Utescu MS, Couture V, Mac-Way F, et al. Determinants of progression of aortic stiffness in hemodialysis patients: a prospective longitudinal study. Hypertension. 2013;62:154-60.

11. Briet M, Collin C, Karras A, et al. Arterial remodeling associates with CKD progression. J Am Soc Nephrol 
2011;22:967-74.

12. Zieman SJ, Melenovsky V, Kass DA. Mechanisms, pathophysiology, and therapy of arterial stiffness. Arterioscler Thromb Vasc Biol 2005;25:932-43.

13. Temmar M, Liabeuf S, Renard C, et al. Pulse wave velocity and vascular calcification at different stages of chronic kidney disease. J Hypertens 2010;28:163-9.

14. Townsend RR, Wimmer NJ, Chirinos JA, et al. Aortic PWV in chronic kidney disease: a CRIC ancillary study. Am J Hypertens 2010;23:282-9.

15. Liu IT, Wu JS, Yang YC, et al. Mild chronic kidney disease associated with greater risk of arterial stiffness in elderly adults. J Am Geriatr Soc 2013;61:1758-62.

16. Elewa U, Fernandez-Fernandez B, Alegre R, et al. Modifiable risk factors for increased arterial stiffness in outpatient nephrology. PLoS One 2015;10:e0123903.

17. Yang L, Lin Y, Ye C, et al. Effects of peritoneal dialysis and hemodialysis on arterial stiffness compared with predialysis patients. Clin Nephrol 2011;75:188-94.

18. Stanifer JW, Jing B, Tolan S, et al. The epidemiology of chronic kidney disease in sub-Saharan Africa: a systematic review and meta-analysis. Lancet Glob Health 2014;2:e174-81.

19. Ulasi II, Arodwe EB, Ijoma CK. LVH in African black patients with chronic renal failure at first evaluation. Ethn Dis 2006; 16:859-64.

20. Kaze FF, Meto DT, Halle MP, et al. Prevalence and determinants of chronic kidney disease in rural and urban Cameroonians: a cross-sectional study. BMC Nephrol 2015;16:117.

21. Kidney Disease: Improving Global Outcomes (KDIGO). Clinical practice guideline for the evaluation and management of chronic kidney disease. Kidney Int Suppl (2011) 2013;3:63-72.

22. Mancia G, Fagard R, Narkiewicz K, et al. 2013 ESH/ESC hypertension guidelines for the Management of Arterial Hypertension: the Task Force for the Management of Arterial Hypertension of the European Society of Hypertension (ESH) and of the European Society of cardiology (ESC). Eur Heart J 2013;34:2159-219.

23. Lemogoum D, Van Bortel L, Najem B, et al. Arterial stiffness and wave reflections in patients with sickle cell disease. Hypertension 2004; 44:924-9.

24. Hametner B, Wassertheurer S, Kropf J, et al. Oscillometric estimation of aortic pulse wave velocity: comparison with intra-aortic catheter measurements. Blood Press Monit 2013;18:173-6.

25. Sarafidis PA, Georgianos PI, Karpetas A, et al. Evaluation of a novel brachial cuff-based oscillometric method for estimating central systolic pressure in hemodialysis patients. Am J Nephrol 2014;40:242-50.

26. Wei W, Tolle M, Zidek W, et al. Validation of the mobilO-Graph: 24 h-blood pressure measurement device. Blood Press Monit 2010;15:225-8.

27. Franssen PM, Imholz BP. Evaluation of the Mobil-OGraph new generation ABPM device using the ESH criteria. Blood Press Monit 2010;15:229-31.

28. Van Bortel LM, Laurent S, Boutouyrie P, et al; on behalf of the Artery Society, the European Society of Hypertension Working Group on Vascular Structure and Function and the European Network for Noninvasive Investigation of Large Arteries. Expert consensus document on the measurement of aortic stiffness in daily practice using carotid-femoral pulse wave velocity. J Hypertens 2012;30:445-8.

29. WHO-IDF. Definition and diagnosis of diabetes mellitus and intermediate hyperglycemia: report of a WHO/ IDF Consultation. Available online: http://www.idf.org/ webdata/docs/WHO_IDF_definition_diagnosis_of_ diabetes.pdf

30. Ferreira AV,Viana MC, Mill JG, et al. Racial differences in aortic stiffness in normotensive and hypertensive adults. J Hypertens 1999;17:631-7.

31. London GM, Marchais SJ, Guerin AP, et al. Arterial structure and function in end-stage renal disease. Nephrol Dial Transplant 2002;17:1713-24.

32. Shinohara K, Shoji T, Tsujimoto Y, et al. Arterial stiffness in predialysis patients with uremia. Kidney Int 2004;65:936-43.

33. Di Iorio B, Nazzaro P, Cucciniello E, et al. Influence of haemodialysis on variability of pulse wave velocity in chronic haemodialysis patients. Nephrol Dial Transplant 2010;25:1579-83.

34. McIntyre NJ, Fluck RJ, McIntyre CW, et al. Determinants of arterial stiffness in chronic kidney disease stage 3. PLos One 2013;8:e55444.

35. Pagoulatou S, Stergiopulos N. Evolution of aortic pressure during normal ageing: A model-based study. PLoS One 2017;12:e0182173.

36. Fischer EC, Zócalo Y, Galli C, et al. Arterial Stiffness and Renal Replacement Therapy: A Controversial Topic. Int J Nephrol 2015;2015:729609.

37. London GM, Marchais SJ, Safar ME, et al. Aortic and large artery compliance in end-stage renal failure. Kidney Int 1990;37:137-42.

38. Charitaki E, Davenport A. Do higher dialysate calcium 
concentrations increase vascular stiffness in haemodialysis patients as measured by aortic pulse wave velocity? BMC Nephrol 2013;14:189.

39. Ford ML, Tomlinson LA, Chapman TPE, et al. Aortic stiffness is independently associated with rate of renal

Cite this article as: Lemogoum D, Halle MP, Mboule RD, Van de Borne P, Bika Lele EC, Kamdem F, Doualla MS, Luma H, Hermans MP, Van Bortel L. Arterial stiffness in black African ancestry patients with chronic kidney disease living in Cameroon. Cardiovasc Diagn Ther 2018;8(4):450-459. doi: $10.21037 /$ cdt.2018.04.04 function decline in chronic kidney disease stages 3 and 4. Hypertension 2010;5 5:1110-5.

40. Wang MC, Tsai WC, Chen JY, et al. Stepwise increase in arterial stiffness corresponding with the stages of chronic kidney disease. Am J Kidney Dis 2005;45:494-501. 